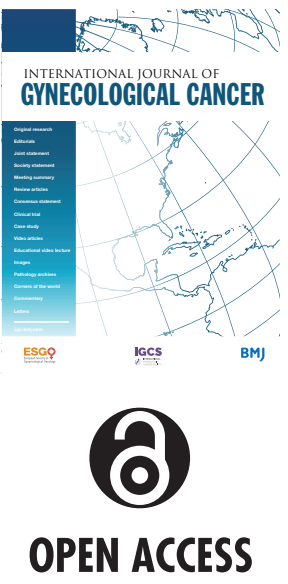

For numbered affiliations see end of article.

Correspondence to Dr Rebecca Kristeleit, Department of Oncology, Guy's and ST Thomas' NHS Foundation Trust, London SE1 9RT, UK; rebecca.kristeleit@ gstt.nhs.uk

For 'Presented at statement' see end of article.

Received 21 June 2021 Accepted 3 September 2021 Published Online First 5 0ctober 2021
Check for updates

(C) IGCS and ESG0 2021. Re-use permitted under CC BY-NC. No commercial re-use. Published by BMJ.

To cite: Kristeleit R, Moreno V, Boni V, et al. Int J Gynecol Cancer 2021;31:1428-1436.

\title{
Doxorubicin plus lurbinectedin in patients with advanced endometrial cancer: results from an expanded phase I study
}

\author{
Rebecca Kristeleit, ${ }^{1}$ Victor Moreno, ${ }^{2}$ Valentina Boni, ${ }^{3}$ Eva M Guerra, ${ }^{4}$ Carmen Kahatt, ${ }^{5}$ \\ Ignacio Romero, ${ }^{6}$ Emiliano Calvo, ${ }^{3}$ Neus Basté, ${ }^{7}$ José A López-Vilariño, ${ }^{5}$ Mariano Siguero, ${ }^{5}$ \\ Vicente Alfaro (i) , ${ }^{8}$ Ali Zeaiter, ${ }^{5}$ Martin Forster ${ }^{9}$
}

\section{HIGHLIGHTS}

- This phase I trial suggests a synergistic effect for lurbinectedin and doxorubicin.

- In the expansion phase, response rate was $42.1 \%$ and duration of response was 7.5 months for the combination of doxorubicin plus lurbinectedin.

- Median progression-free survival was 7.7 months and median overall survival was 14.2 months.

\section{ABSTRACT}

Objective Second-line treatment of endometrial cancer is an unmet medical need. We conducted a phase I study evaluating lurbinectedin and doxorubicin intravenously every 3 weeks in patients with solid tumors. The aim of this study was to characterise the efficacy and safety of lurbinectedin and doxorubicin for patients with endometrial cancer.

Methods Thirty-four patients were treated: 15 patients in the escalation phase (doxorubicin $50 \mathrm{mg} / \mathrm{m}^{2}$ and lurbinectedin $3.0-5.0 \mathrm{mg}$ ) and 19 patients in the expansion cohort (doxorubicin $40 \mathrm{mg} / \mathrm{m}^{2}$ and lurbinectedin $2.0 \mathrm{mg} /$ $\mathrm{m}^{2}$ ). All histological subtypes were eligible and patients had received one to two prior lines of chemotherapy for advanced disease. Antitumor activity was evaluated every two cycles according to the Response Evaluation Criteria in Solid Tumors version 1.1. Adverse events were graded according to the National Cancer Institute-Common Terminology Criteria for Adverse Events version 4. Results Median age (range) was 65 (51-78) years. Eastern Cooperative Oncology Group performance status was up to 1 in $97 \%$ of patients. In the escalation phase, 4 (26.7\%) of 15 patients had confirmed response: two complete and two partial responses $(95 \% \mathrm{Cl} 7.8 \%$ to $55.1 \%$ ). Median duration of response was 19.5 months. Median progression-free survival was 7.3 (2.5 to 10.1) months. In the expansion cohort, confirmed partial response was reported in $8(42.1 \%)$ of 19 patients $(95 \% \mathrm{Cl} 20.3 \%$ to $66.5 \%)$. Median duration of response was 7.5 (6.4 to not reached) months, median progression-free survival was 7.7 (2.0 to 16.7) months and median overall survival was 14.2 (4.5 to not reached) months. Fatigue ( $26.3 \%$ of patients), and transient and reversible myelosuppression (neutropenia, $78.9 \%$; febrile neutropenia, 21.1\%; thrombocytopenia, 15.8\%) were the main grade 3 and higher toxicities in the expanded cohort. Conclusions In patients with recurrent advanced endometrial cancer treated with doxorubicin and lurbinectedin, response rates (42\%) and duration of response (7.5 months) were favorable. Further evaluation of doxorubicin and lurbinectedin is warranted in this patient population.

\section{INTRODUCTION}

Relapsed endometrial cancer has a poor prognosis with a median survival of 12-15 months. This patient population has a significant unmet clinical need and optimal treatment is yet to be established. ${ }^{12}$ There are promising signs of clinical efficacy with antiprogrammed death-1 targeting drugs for mismatch repair deficient relapsed endometrial cancer and combination treatment with pembrolizumab plus lenvatinib in microsatellite stable recurrent endometrial cancer. Recently, dostarlimab was approved for second-line treatment of adult patients with advanced or recurrent mismatch repair deficient disease. Biomarkers such as overexpression of polymerase epsilon, proto-oncogene $\mathrm{Neu}$, and microsatellite instability or mismatch repair deficiency are increasingly being used in the setting of recurrent disease. $^{34}$ However, single agent chemotherapy remains the most frequent treatment for relapsed endometrial cancer. $^{2}$

Lurbinectedin is a minor groove targeting DNA binder that interacts with specific factors involved in DNA repair and transcription pathways, thereby inhibiting trans-activated transcription in tumor cells, and also transcription and secretion of selected cytokines by tumor-associated macrophages. In June 2020, the United States Food and Drug Administration (FDA) granted accelerated approval to lurbinectedin for adult patients with metastatic small cell lung cancer with disease progression on or after platinum-based chemotherapy. ${ }^{5} \quad$ Lurbinectedin plus doxorubicin showed synergistic antitumor effect in small cell lung cancer xenografted tumors. Improved activity with this combination and activity observed for lurbinectedin 
in a study of humans ${ }^{6}$ prompted a phase I trial to evaluate this combination in advanced solid tumors. ${ }^{7}$ During the dose escalation, activity was promising in two tumor types-small cell lung cancer and endometrial cancer-and expansion cohorts were evaluated. We show the results observed in advanced endometrial cancer during dose escalation and cohort expansion, exploring a modified regimen to reduce myelosuppression.

\section{METHODS}

Patients were enrolled in sites from Spain and the United Kingdom. The study followed the International Conference on Harmonization Good Clinical Practice guidelines, and was approved by the respective Research Ethics Committees for each country. Written informed consent was obtained from all patients. The trial is registered in the European Clinical Trials Register database (EudraCT 2010-02429125) and at ClinicalTrials.gov (NCT01970540).

\section{Eligibility Criteria}

Eligible patients were aged 18 years and older with endometrial cancer treated with one or two prior lines of cytotoxic chemotherapy for advanced disease and were anthracycline naïve; had documented disease progression during or immediately after their last therapy in those treated in the expansion cohort; had recovered from previous toxicities (at least 3 weeks since last anticancer therapy); had life expectancy of 3 months or more; had Eastern Cooperative Oncology Group performance status of 2 or lower; had normal left ventricular ejection fraction; and had adequate bone marrow, hepatic and renal function, including albumin $\geq 3.0 \mathrm{~g} / \mathrm{dL}$. Prior endocrine therapy was allowed (not considered a line of treatment).

Patients were excluded if they had symptomatic progressive or corticosteroid-requiring brain metastases or leptomeningeal involvement; had prior bone marrow/stem cell transplantation, cardiac disease, uncontrolled alcohol consumption or cirrhosis, active uncontrolled infection, or any disease potentially interfering with the study outcome.

\section{Study Design and Treatment}

Study design is summarized in Figure 1. Dose escalation has been described elsewhere. ${ }^{7}$ Briefly, 74 patients with advanced solid tumors (15 patients with endometrial cancer) were included using a 3+3 cohort design. Four dose levels were evaluated: fixed doxorubicin $50 \mathrm{mg} / \mathrm{m}^{2}$ as an intravenous bolus with escalating flat doses of lurbinectedin $(3.0,3.5,4.0$ and $5.0 \mathrm{mg})$ intravenously over 1 hour on day 1 every 3 weeks. The recommended dose was doxorubicin $50 \mathrm{mg} / \mathrm{m}^{2}$ plus lurbinectedin $4.0 \mathrm{mg}$.

After identification of the recommended dose and encouraging antitumor activity, expansion cohorts were started in small cell lung cancer and advanced endometrial cancer. Results for the expanded small cell lung cancer cohort are described elsewhere. ${ }^{7}$ This report focuses on the endometrial cohort. In this expanded cohort, patients were treated with a new recommended dose, doxorubicin $40 \mathrm{mg} /$ $\mathrm{m}^{2}$ intravenous bolus plus lurbinectedin $2.0 \mathrm{mg} / \mathrm{m}^{2} 1$ hour intravenous infusion, using the same schedule (day 1 every 3 weeks) as the dose escalation phase. Doxorubicin dose was lowered to $40 \mathrm{mg} / \mathrm{m}^{2}$ and lurbinectedin dose was transformed to a body surface area based dose to reduce severe myelosuppression. This change was introduced in a protocol amendment because doselimiting toxicities were found in several patients with small cell lung cancer and endometrial cancer at the initial recommended dose (doxorubicin $50 \mathrm{mg} / \mathrm{m}^{2}$ plus lurbinectedin $4.0 \mathrm{mg}$.). All dose-limiting toxicities reported in patients with endometrial cancer were neutropenia related and $86.4 \%$ of patients with small cell lung cancer had grade 4 neutropenia. These findings suggested that the initial recommended dose might not be feasible in these patient populations. Both doxorubicin and lurbinectedin doses were capped at a body surface area of $2.0 \mathrm{~m}^{2}$. Furthermore, to prevent cardiomyopathy, ${ }^{8}$ patients who received 10 cycles of the combination (before a

Dose escalation phase

$\mathrm{n}=74$ (15 patients with endometrial cancer)

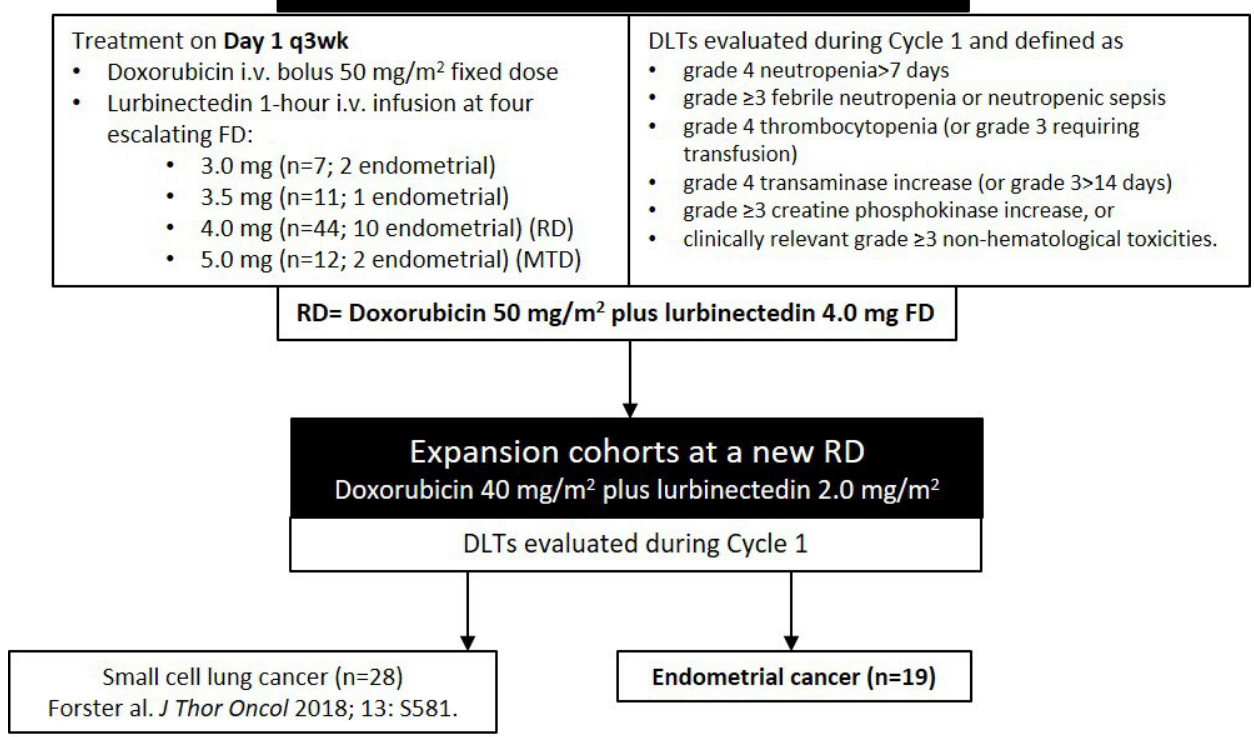

Figure 1 Study design. DLT, dose-limiting toxicity; FD, flat dose; MTD, maximum tolerated dose; q3wk, every 3 weeks; RD, recommended dose. 


\section{Original research}

cumulative dose of $450 \mathrm{mg} / \mathrm{m}^{2}$ was reached), or discontinued doxorubicin due to a cardiac adverse event, continued treatment with lurbinectedin alone $\left(4.0 \mathrm{mg} / \mathrm{m}^{2}\right.$ on day 1 every 3 weeks).

All patients received standard antiemetic prophylaxis before each infusion. ${ }^{9}$ Treatment was given until disease progression, unacceptable toxicity, intercurrent illness precluding study continuation, patient refusal and/or non-compliance with study requirements, treatment delay greater than 15 days (except if clear clinical benefit), and requirement of more than two dose reductions.

\section{Study Assessments}

Antitumor activity was evaluated every two cycles according to the Response Evaluation Criteria in Solid Tumors version 1.1 (responses confirmed at least 4 weeks later). Overall response rate was the percentage of patients with confirmed complete or partial response. Time-to-event parameters were duration of response and progressionfree survival. Progression-free survival was defined as the time from the date of first infusion of study treatment to the date of progression or death (due to any cause). ${ }^{10}$ Overall survival was reported only in the dose expansion phase as an exploratory assessment. Overall survival was defined as the time from the date of first infusion of study treatment to the date of death (due to any cause). ${ }^{10}$

Adverse events were coded with the Medical Dictionary for Regulatory Activities version 14.1 and graded using the National Cancer Institute-Common Terminology Criteria for Adverse Events version 4. Laboratory abnormalities (hematological and biochemical) were measured weekly in the first cycle, and on day 1 and day 10 in further cycles, and graded using the National Cancer InstituteCommon Terminology Criteria for Adverse Events version 4.

\section{Statistical Analysis}

Continuous variables were presented with summary statistics and categorical variables in frequency tables. Time-to-event variables were calculated using the Kaplan-Meier approach. Binomial exact distribution was used to calculate $95 \% \mathrm{Cl}$ intervals for categorical variables.

\section{RESULTS}

\section{Dose Feasibility for the New Recommended Dose}

Forty-seven patients were treated with doxorubicin $40 \mathrm{mg} / \mathrm{m} 2$ plus lurbinectedin $2.0 \mathrm{mg} / \mathrm{m} 2$ every 3 weeks in the expansion cohort: 28 patients with small cell lung cancer and 19 patients with endometrial cancer. Dose-limiting toxicities occurred in four of 46 evaluable patients $(9 \%)$; this percentage was lower than the threshold (one third) established by the study protocol to define the recommended dose, thereby confirming dose feasibility. All dose-limiting toxicities occurred in small cell lung cancer patients, and comprised grade $3 / 4$ febrile neutropenia $(n=2)$, grade four thrombocytopenia, and grade three decreased appetite $\left(n=1\right.$ each). ${ }^{11}$

\section{Characteristics of Patients With Endometrial Cancer}

Thirty-four patients with advanced endometrial cancer were treated in this phase I study: 15 patients during the escalation phase and 19 patients in the expansion cohort (Table 1). Median age was 64 (range 51-78) years in the escalation phase and 66 (55-73) years in the expansion cohort, and most patients (23/34; 67.6\%) had Eastern Cooperative Oncology performance status score of 1.
Table 1 Baseline characteristics of patients with endometrial cancer

\begin{tabular}{|c|c|c|c|c|}
\hline & \multicolumn{2}{|c|}{$\begin{array}{l}\text { Dose escalation phase } \\
(n=15)^{\star}\end{array}$} & \multicolumn{2}{|c|}{$\begin{array}{l}\text { Expanded cohort } \\
(n=19) \dagger\end{array}$} \\
\hline & $\mathbf{N}$ & $\%$ & $\mathbf{N}$ & $\%$ \\
\hline $\begin{array}{l}\text { Median age (range) } \\
\text { (years) }\end{array}$ & $64(51-78)$ & & $66(55-73)$ & \\
\hline \multicolumn{5}{|c|}{ ECOG performance status } \\
\hline 0 & 4 & 26.7 & 6 & 31.6 \\
\hline 1 & 11 & 73.3 & 12 & 63.2 \\
\hline 2 & - & - & 1 & 5.3 \\
\hline $\begin{array}{l}\text { Median BSA (range) } \\
\left(m^{2}\right)\end{array}$ & \multicolumn{2}{|l|}{$1.7(1.4-2.1)$} & \multicolumn{2}{|l|}{$1.8(1.6-2.3)$} \\
\hline $\begin{array}{l}\text { Bulky disease } \\
\text { (lesion }>50 \mathrm{~mm} \text { ) }\end{array}$ & 5 & 38.5 & 4 & 21.1 \\
\hline Visceral disease & 7 & 46.7 & 7 & 36.8 \\
\hline \multicolumn{5}{|l|}{ Histology } \\
\hline Endometrioid & 11 & 73.3 & 15 & 78.9 \\
\hline Carcinosarcoma & 3 & 20.0 & 3 & 15.8 \\
\hline Clear cell & 1 & 6.7 & - & - \\
\hline Serous/papillary & - & - & 1 & 5.3 \\
\hline $\begin{array}{l}\text { Median No of sites } \\
\text { (range) }\end{array}$ & \multicolumn{2}{|l|}{$2(1-5)$} & \multicolumn{2}{|l|}{$2(1-3)$} \\
\hline \multicolumn{5}{|c|}{ Most common metastatic sites } \\
\hline Lymph nodes & 9 & 60.0 & 10 & 52.6 \\
\hline Lung & 6 & 40.0 & 5 & 26.3 \\
\hline Peritoneum & 2 & 13.3 & 8 & 42.1 \\
\hline Pelvis & 2 & 13.3 & 3 & 15.8 \\
\hline Liver & 2 & 13.3 & 2 & 10.5 \\
\hline \multicolumn{5}{|l|}{ Prior therapy } \\
\hline Chemotherapy & 15 & 100.0 & 19 & 100.0 \\
\hline Surgery & 10 & 66.7 & 15 & 78.9 \\
\hline Radiotherapy & 6 & 40.0 & 12 & 63.2 \\
\hline Hormonal therapy & 4 & 26.7 & 4 & 21.1 \\
\hline Biological therapy & 1 & 6.7 & 2 & 10.5 \\
\hline \multicolumn{5}{|l|}{$\begin{array}{l}\text { Prior chemotherapy } \\
\text { lines }\end{array}$} \\
\hline Median (range) & $1(1-2)$ & & $1(1-2)$ & \\
\hline 1 & 11 & 73.3 & 15 & 78.9 \\
\hline 2 & 4 & 26.7 & 4 & 21.1 \\
\hline $\begin{array}{l}\text { Lines for advanced } \\
\text { disease, median } \\
\text { (range) }\end{array}$ & $1(0-2)$ & & $1(0-2)$ & \\
\hline \multicolumn{5}{|c|}{ Most common prior anticancer agents } \\
\hline Platinum compounds & 9 & 60.0 & 16 & 84.2 \\
\hline Taxanes & 8 & 53.3 & 15 & 78.9 \\
\hline Platinum-free interval & \multicolumn{2}{|l|}{$4.5(0.3-17.1)$} & \multicolumn{2}{|l|}{$4.3(0.3-16.5)$} \\
\hline
\end{tabular}

${ }^{*}$ Patients treated at fixed doxorubicin dose $\left(50 \mathrm{mg} / \mathrm{m}^{2}\right)$ and escalating lurbinectedin doses (ranging from 3.0 to $5.0 \mathrm{mg}$ flat dose) on day 1 every 3 weeks.

†Patients treated at the recommended dose of doxorubicin $40 \mathrm{mg} / \mathrm{m}^{2}$ plus lurbinectedin $2.0 \mathrm{mg} / \mathrm{m}^{2}$ on day 1 every 3 weeks.

BSA, body surface area; ECOG, Eastern Cooperative Oncology Group.;

The most common histological type was endometrioid ( 26 patients; $76.5 \%)$. The median number of prior lines for advanced disease was one (range zero to two), with platinum and taxanes as the most common agents. Median platinum-free interval was 4.5 (range 
Table 2 Efficacy results with lurbinectedin plus doxorubicin in patients with endometrial cancer

Dose escalation phase $(n=15)^{*}$

Expanded cohort $(n=19) \dagger$

$\begin{array}{lll}\text { Objective response per RECIST v1.1. } & & \\ \text { CR, } \mathrm{n}(\%) & 2(13.3) & - \\ \mathrm{PR}, \mathrm{n}(\%) & 2(13.3) & 8(42.1) \\ \mathrm{SD} \geq 4 \text { months, } \mathrm{n}(\%) & 5(33.3) & 4(21.1) \\ \mathrm{SD}<4 \text { months, } \mathrm{n}(\%) & 3(20.0) & 3(15.8) \\ \mathrm{PD}, \mathrm{n}(\%) & 3(20.0) & 4(21.1) \\ \text { ORR, \% (95\% Cl) } & 26.7(7.8 \text { to } 55.1) & 42.1(20.3 \text { to } 66.5) \\ \text { Disease control rate }(95 \% \mathrm{Cl}) \ddagger & 80.0(51.9 \text { to } 95.7) & 78.9(54.4 \text { to } 93.9) \\ \text { Clinical benefit rate }(95 \% \mathrm{Cl}) \S & 60.0(32.3 \text { to } 83.7) & 63.2(38.4 \text { to } 83.7) \\ \text { Median DoR (months) }(95 \% \mathrm{Cl}) & 19.5(8.2 \text { to } \mathrm{NR}) & 7.5(6.4 \text { to } \mathrm{NR}) \\ \text { Median PFS (months) }(95 \% \mathrm{Cl}) & 7.3(2.5 \text { to } 10.1) & 7.7(2.0 \text { to } 16.7) \\ \text { Median OS (months) }(95 \% \mathrm{Cl}) & \mathrm{NA} & 14.2(4.5 \text { to NR) }\end{array}$

*Patients treated at fixed doxorubicin dose $\left(50 \mathrm{mg} / \mathrm{m}^{2}\right)$ and escalating lurbinectedin doses (ranging from 3.0 to $5.0 \mathrm{mg}$ flat dose) on day 1 every 3 weeks.

†Patients treated at the recommended dose of doxorubicin $40 \mathrm{mg} / \mathrm{m}^{2}$ plus lurbinectedin $2.0 \mathrm{mg} / \mathrm{m}^{2}$ on day 1 every 3 weeks.

$\ddagger$ Objective response plus stable disease.

§Objective response plus stable disease $\geq 4$ months.

$\mathrm{CR}$, complete response; DoR, duration of response; NA, not available; NR, not reached; ORR, overall response rate; OS, overall

survival; PD, disease progression; PFS, progression-free survival; PR, partial response; SD, stable disease.

0.3-17.1) months in the escalation phase and $4.3(0.3-16.5)$ months in the expansion cohort.

\section{Treatment Exposure}

In the escalation phase, the median number of cycles per patient was 8 (range 1-52). Median relative dose intensity for doxorubicin and lurbinectedin was $95.0 \%$ and $83.7 \%$, respectively. Treatmentrelated cycle delays, dose reductions and discontinuations were observed in $79 \%, 71 \%$ and $13 \%$ of patients, mainly because of hematological toxicity. In the expansion cohort, the median number of cycles per patient was 9 (range 1-28). Median relative dose intensity for doxorubicin and lurbinectedin was $95.0 \%$ and $90.3 \%$, respectively. Treatment-related cycle delays, dose reductions and discontinuations were observed in $65 \%, 47 \%$ and $11 \%$ of patients, also mainly because of hematological toxicity.

\section{Efficacy}

In the escalation phase, four (26.7\%) of 15 patients had confirmed responses: two complete responses and two partial responses (95\% $\mathrm{Cl} 7.8 \%$ to $55.1 \%)$. The two patients with complete response were treated with lurbinectedin 4.0 and $5.0 \mathrm{mg} / \mathrm{m}^{2}$; the two patients with partial response were treated with lurbinectedin 3.0 and $4.0 \mathrm{mg} / \mathrm{m}^{2}$. Median duration of response was 19.5 (8.2 to not reached) months and median progression-free survival was 7.3 (2.5 to 10.1) months (Table 2).

In the expansion cohort, 8 (42.1\%) of 19 patients had confirmed partial responses $(95 \% \mathrm{Cl} 20.3 \%$ to $66.5 \%)$. Median duration of response was 7.5 (6.4 to not reached) months, median progressionfree survival was 7.7 (2.0 to 16.7) months and median overall survival was 14.2 (4.5 to not reached) months (Table 2). Overall, $69 \%$ of patients had reduction in tumor sized as based on imaging assessment, with activity mostly observed in the endometrioid type (Figure 2). Of note, the overall response rate in patients with endometrioid carcinoma $(n=26)$ was $36.4 \%(95 \% \mathrm{Cl} 10.9 \%$ to $69.2 \%)$ in the escalation phase and $46.7 \%$ (21.3\% to $73.4 \%)$ in the expansion cohort. The overall response rate in patients with non-endometrioid types $(n=8)$ was $0 \%$ in the escalation phase and $25 \%(0.6 \%$ to $80.6 \%$ in the expansion cohort. Duration of response in each responder patient is shown in Figure 3.

\section{Safety}

The most frequent treatment-related (or with unknown relationship) adverse events reported in the escalation phase were fatigue $(80.0 \%)$, nausea $(80.0 \%)$, decreased appetite $(60.0 \%)$, mucositis (46.7\%) and vomiting (46.7\%). Grade 3 and higher adverse events consisted of febrile neutropenia (40\%), fatigue $(20 \%)$, and diarrhea, nausea and vomiting ( $7 \%$ each). However, patients received different doses, some being lower or higher than the recommended dose. Hence, the safety results are more focused on the patients treated in the expansion cohort (Table 3). The most frequent adverse

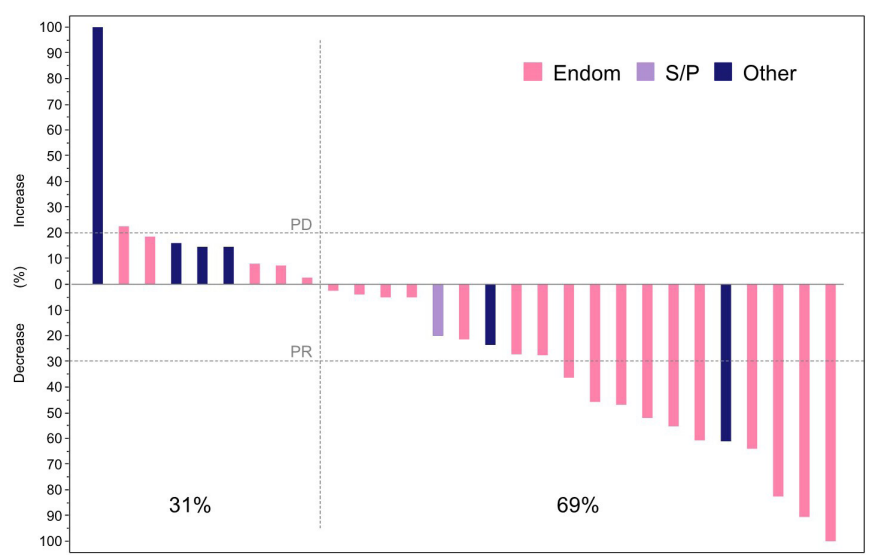

Figure 2 Waterfall plot showing maximum variation of target lesions size. Endom, endometrioid; PD, disease progression; PR, partial response; S/P, serous/papillary. 


\section{Original research}

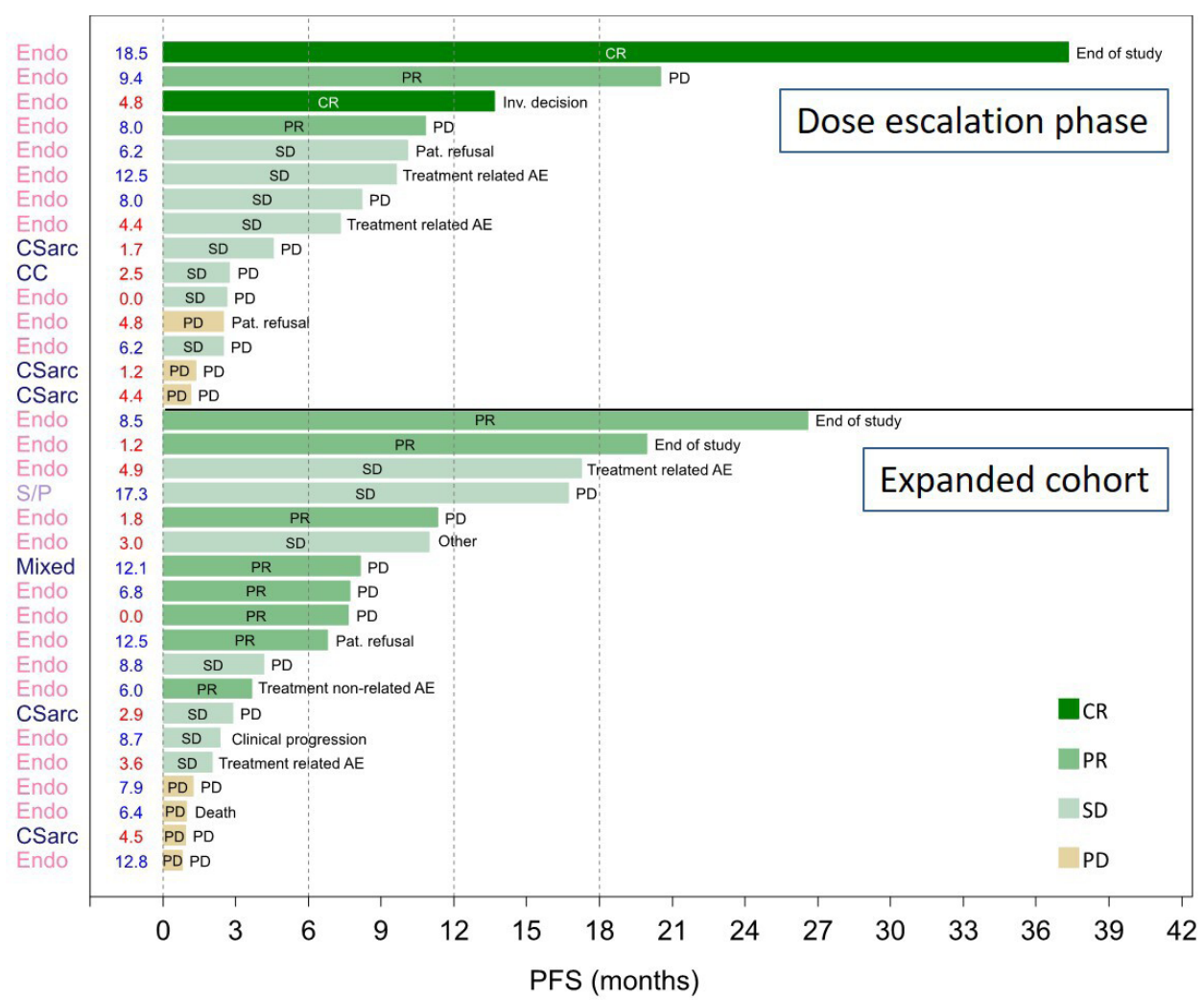

Figure 3 Swimmer plot showing duration of response. Each bar represents one patient with endometrial cancer $(n=34)$. Data shown on the left of each bar are the histological type and the duration of response. AE, adverse event; CR, complete response; PD, disease progression; PR, partial response; SD, stable disease.

events were fatigue $(78.9 \%)$, nausea $(68.4 \%)$, alopecia $(52.6 \%)$, constipation $(42.1 \%)$, and diarrhea, mucositis and vomiting $(26.3 \%$ each). No cardiac toxicities related to left ventricular ejection fraction occurred. Grade 3 and higher adverse events consisted of fatigue $(26.3 \%)$, febrile neutropenia $(21.1 \%)$, and diarrhea, lower respiratory tract infection, neutropenic infection and renal failure acute $(5.3 \%$ each).

In the escalation phase, grade 3 and higher hematological laboratory abnormalities consisted of anemia $(80.0 \%)$, neutropenia $(93.3 \%$; grade $4,86.7 \%)$, and thrombocytopenia (46.6\%; grade 4 , $33.3 \%)$. In the expansion cohort, grade 3 and higher hematological laboratory abnormalities consisted of anemia (31.6\%), neutropenia (78.9\%; grade 4, 63.2\%), and thrombocytopenia (15.8\%; grade 4 , $10.5 \%$ ) (Table 3). Grade 4 neutropenia was transient with a median duration of 2 days (range 1-6 days). Most biochemical laboratory abnormalities were grade 1 or 2 with no effects on the study treatment.

One patient died due to a doxorubicin-related adverse event, acute monocytic leukemia, which was detected 129 days after the last study treatment infusion (during follow-up for survival). This patient had previously received pelvic radiotherapy and brachytherapy as well as carboplatin and paclitaxel.

\section{DISCUSSION}

\section{Summary of Main Results}

The overall response rate was $42.1 \%$, median duration of response was 7.5 months, median progression-free survival was 7.7 months and median overall survival was 14.2 months in patients with recurrent advanced endometrial cancer treated with doxorubicin $\left(40 \mathrm{mg} / \mathrm{m}^{2}\right)$ and lurbinectedin $\left(2.0 \mathrm{mg} / \mathrm{m}^{2}\right)$ on day 1 every 3 weeks.

\section{Results in the Context of Published Literature}

Based on the results from KEYNOTE-146/Study 111, the US FDA granted accelerated approval to pembrolizumab/lenvatinib for the treatment of patients with advanced endometrial carcinoma that is not microsatellite instability high or mismatch repair deficient with disease progression following prior systemic therapy and in candidates for curative surgery or radiation. ${ }^{12}$ In this phase $\mathrm{I} / / \mathrm{l}$ study, the final primary efficacy analysis results in a group of 94 patients with microsatellite stable-H/mismatch repair proficient disease showed an overall response rate of $37.2 \%$, disease control rate ofs $84.0 \%$ and clinical benefit rate of $58.5 \% .{ }^{13}$ Time-to-event data were not available, and two confirmatory phase III trials (ClinicalTrials. gov identifier NCT03884101 and NCT03517449) are currently underway. Despite promising clinical efficacy, this study reported treatment-related adverse events leading to dose interruptions in $74 \%$ of patients and dose reductions in $53 \%$ of patients, with a high discontinuation rate (9\%). Doxorubicin $40 \mathrm{mg} / \mathrm{m}^{2}$ plus lurbinectedin $2.0 \mathrm{mg} / \mathrm{m}^{2}$ every 3 weeks in combination showed similar antitumor activity than pembrolizumab/lenvatinib: overall response rate of $42.1 \%$ versus $37.2 \%$; disease control rate of $78.9 \%$ versus $84.0 \%$, and clinical benefit rate of $63.2 \%$ versus $58.5 \%$; and activity was seen across both endometrioid and non-endometrioid histologies.

Furthermore, the results observed for the doxorubicin plus lurbinectedin combination compare favorably with those previously 
Table 3 Treatment-related adverse events ( $>10 \%$ of patients or grade $>3$ ) and laboratory abnormalities regardless of relationship, in patients with advanced endometrial cancer treated at the recommended dose: doxorubicin $40 \mathrm{mg} / \mathrm{m}^{2}$ and lurbinectedin $2.0 \mathrm{mg} / \mathrm{m}^{2}$ on day one every 3 weeks

\begin{tabular}{|c|c|c|c|c|c|c|c|c|}
\hline & \multicolumn{8}{|c|}{ Expansion cohort ( $n=19$ patients) } \\
\hline & \multicolumn{8}{|c|}{ NCI-CTCAE grade } \\
\hline & \multicolumn{2}{|c|}{$1 / 2$} & \multicolumn{2}{|c|}{3} & \multicolumn{2}{|c|}{4} & \multicolumn{2}{|c|}{ Total $^{*} \dagger$} \\
\hline \multicolumn{9}{|l|}{ Treatment-related adverse events $\ddagger$} \\
\hline Fatigue & 10 & 52.6 & 5 & 26.3 & - & - & 15 & 78.9 \\
\hline Constipation & 8 & 42.1 & - & - & - & - & 8 & 42.1 \\
\hline Diarrhea & 4 & 21.1 & 1 & 5.3 & - & - & 5 & 26.3 \\
\hline Mucositis & 5 & 26.3 & - & - & - & - & 5 & 26.3 \\
\hline Vomiting & 5 & 26.3 & - & - & - & - & 5 & 26.3 \\
\hline Myalgia & 3 & 15.8 & - & - & - & - & 3 & 15.8 \\
\hline Dyspepsia & 2 & 10.5 & - & - & - & - & 2 & 10.5 \\
\hline Epistaxis & 2 & 10.5 & - & - & - & - & 2 & 10.5 \\
\hline Pain in extremity & 2 & 10.5 & - & - & - & - & 2 & 10.5 \\
\hline Palmar-plantar erythrodysesthesia syndrome & 2 & 10.5 & - & - & - & - & 2 & 10.5 \\
\hline Palpitations & 2 & 10.5 & - & - & - & - & 2 & 10.5 \\
\hline Peripheral edema & 2 & 10.5 & - & - & - & - & 2 & 10.5 \\
\hline Peripheral sensory neuropathy & 2 & 10.5 & - & - & - & - & 2 & 10.5 \\
\hline Acute renal failure & - & - & 1 & 5.3 & - & - & 1 & 5.3 \\
\hline \multicolumn{9}{|l|}{ Laboratory abnormalities } \\
\hline Thrombocytopenia & 11 & 57.9 & 1 & 5.3 & 2 & 10.5 & 14 & 73.7 \\
\hline AP increased & 10 & 52.6 & 1 & 5.3 & - & - & 11 & 57.9 \\
\hline ALT increased & 8 & 42.1 & 2 & 10.5 & - & - & 10 & 52.6 \\
\hline AST increased & 8 & 42.1 & - & - & - & - & 8 & 42.1 \\
\hline Bilirubin increased & 2 & 10.5 & - & - & - & - & 2 & 10.5 \\
\hline
\end{tabular}

*Adverse events and laboratory abnormalities ordered by incidence from higher to lower.

†No grade 5 adverse events were reported.

łIncluding adverse events with unknown relationship.

AP, alkaline phosphatase; ALT, alanine aminotransferase; AST, aspartate aminotransferase; NCI-CTCAE, National Cancer Institute Common

Terminology Criteria for Adverse Events, v4.

observed in advanced or relapsed endometrial cancer with several agents tested in the second-line setting. Overall, antitumor activity in these previous studies was modest, with response rate ranging between $0 \%$ and $27 \%$, paclitaxel being the most active (Table 4).

The median progression-free survival (7.7 months) and median overall survival (14.2 months) observed with doxorubicin plus lurbinectedin can be considered promising. The median progression-free survival was similar to the 7.4 months reported with pembrolizumab/lenvatinib. ${ }^{13}$ Shorter median progression-free survival (3.4-4.2 months) and overall survival (10.5-12.3 months) have been found with palliative chemotherapy ${ }^{14}$ and antiangiogenic therapies ${ }^{15}$ in recurrent endometrial cancer.

Activity with lurbinectedin has been found in other studies conducted in advanced endometrial cancer. In a phase II basket study, 40 patients with endometrial cancer treated with lurbinectedin $3.2 \mathrm{mg} / \mathrm{m}^{2}$ every 3 weeks showed an overall response rate of $12.5 \%$ (one complete and four partial responses), median 


\section{Original research}

Table 4 Clinical trials evaluating chemotherapy in second-line treatment of relapsed endometrial cancer

\begin{tabular}{|c|c|c|c|}
\hline Drugs & No of patients & ORR (\%) & Reference (year) \\
\hline Cisplatin & 25 & 4 & Thigpen et al. (1984) $)^{19}$ \\
\hline Cyclophosphamide & 15 & 0 & Pawinski et al.(1999) ${ }^{20}$ \\
\hline Dactinomycin & 27 & 12 & Moore et al. $(1999)^{21}$ \\
\hline Docetaxel (weekly) & 27 & 8 & Garcia et al. (2008) ${ }^{22}$ \\
\hline Doxorubicin & $\begin{array}{l}18 \\
255\end{array}$ & $\begin{array}{l}0 \\
14\end{array}$ & $\begin{array}{l}\text { Di Legge et al. (2011) } \\
\text { Miller et al. }(2018)^{1723}\end{array}$ \\
\hline Doxorubicin (pegylated) & $\begin{array}{l}42 \\
19\end{array}$ & $\begin{array}{l}10 \\
11^{*}\end{array}$ & $\begin{array}{l}\text { Muggia et al. (2002) } \\
\text { Escobar et al. (2003) } 2425\end{array}$ \\
\hline Etoposide & 22 & 0 & Rose et al.(1996) ${ }^{26}$ \\
\hline Gemcitabine & 23 & 4 & Tait et al. (2011) ${ }^{27}$ \\
\hline Ifosfamide & 40 & 15 & Sutton et al. $(1994)^{28}$ \\
\hline Ixabepilone & 52 & 12 & Dizon et al. (2009) ${ }^{29}$ \\
\hline Ixabepilone vs paclitaxel or doxorubicin† & $223 / 223$ & $15 / 16$ & McMeekin et al. (2015) ${ }^{14}$ \\
\hline Oxaliplatin & 54 & 14 & Fracasso et al. (2006) \\
\hline Paclitaxel $\ddagger$ & 44 & 27 & Lincoln et al. (2003) \\
\hline Topotecan & 22 & 9 & Miller et al. (2002) ${ }^{32}$ \\
\hline Zoptarelin (AEZ108)§ & 256 & 12 & Miller et al. $(2018)^{17}$ \\
\hline Lurbinectedin & 40 & 13 & Forster et al. (2017) ${ }^{16}$ \\
\hline Paclitaxel plus lurbinectedin & 11 & 27 & Forster et al. (2017) ${ }^{16}$ \\
\hline Doxorubicin plus lurbinectedin & $\begin{array}{l}15 \rrbracket \\
19^{* *}\end{array}$ & $\begin{array}{l}27 \\
44\end{array}$ & $\begin{array}{l}\text { Current phase I trial } \\
\text { (NCT01970540) }\end{array}$ \\
\hline
\end{tabular}

${ }^{*} 21 \%$ response: RECIST (two patients; $11 \%$ ) and CA-125 response (defined as major symptomatic improvement associated with $>50 \%$ decline in CA-125 value) (other two patients).

†Phase III randomized trial.

‡Patients had no prior paclitaxel.

§Top-line results from a phase III trial (NCT01767155) evaluating zoptarelin compared with doxorubicin showed no significant difference

in the primary endpoint (overall survival), but also in secondary endpoints like progression-free survival.

१Doxorubicin $50 \mathrm{mg} / \mathrm{m}^{2}$ plus lurbinectedin $3-5 \mathrm{mg}$ flat dose.

${ }^{*}$ Doxorubicin $40 \mathrm{mg} / \mathrm{m}^{2}$ plus lurbinectedin $2.0 \mathrm{mg} / \mathrm{m}^{2}$.

ORR, overall response rate; RECIST, Response Evaluation Criteria in Solid Tumors.

duration of response of $\geq 4.3$ months and median progressionfree survival of $\geq 2.5$ months. ${ }^{16}$ Another trial evaluating lurbinectedin/paclitaxel showed an overall response rate of $27 \%$ (three partial responses), median duration of response of 6.1 months and median progression-free survival of 1.9 months in a small cohort of 11 patients. ${ }^{16}$ However, the most remarkable antitumor activity in terms of overall response rate and progression-free survival has been found in the current trial with lurbinectedin/ doxorubicin.

Doxorubicin has shown low antitumor activity in second-line endometrial cancer. A phase III trial compared ixabepilone with paclitaxel or doxorubicin as the control arm: the overall response rate was $16 \%$ and the median overall survival was 12.3 months in the control arm. ${ }^{14}$ Another phase III trial compared zoptarelin with doxorubicin alone: the overall response rate in the doxorubicin arm was $14 \%$, the clinical benefit rate was $52 \%$, and the median overall survival was 10.8 months. ${ }^{17}$ Therefore, the results from the current phase I trial suggest a synergistic effect of both lurbinectedin and doxorubicin when given in combination, concordant with observations in preclinical studies.

To date, most chemotherapeutic options for advanced endometrial cancer have been associated with limited efficacy, and some with significant toxicity. Subsequent efforts are focused on exploiting the molecular biology of this disease for targetspecific and immunotherapeutic approaches. However, patients with endometrial cancer are often older than 65 years and have comorbidities, and tolerability of treatment is an important consideration, especially with targeted therapy combinations. Pembrolizumab/lenvatinib is associated with substantial toxicity, with treatment-related and grade 3 or 4 adverse events observed in $97 \%$ and $67 \%$ of patients in the KEYNOTE-146/Study $111 .{ }^{13}$ The safety analysis supporting the accelerated approval included Study 111 and monotherapy trials that evaluated the contribution of each drug to the safety profile of the combination. Fatal adverse reactions occurred in $3 \%$ of patients receiving the combination, including gastrointestinal perforation, reversible posterior leukoencephalopathy syndrome with intraventricular hemorrhage, and intracranial hemorrhage. Treatment discontinuation due to adverse reactions occurred in $21 \%$ and serious adverse events in $52 \%$ of patients. ${ }^{12}$ Hypothyroidism was the most frequent adverse event occurring in a greater proportion of patients (48\%). ${ }^{13}$ Immune-mediated adverse events or infusionrelated reactions with pembrolizumab occurred in $57.4 \%$ of patients. ${ }^{12}$ In contrast, doxorubicin/lurbinectedin was generally 
well tolerated, and associated with manageable and predictable myelotoxicity. Patients received a median of nine cycles and relative dose intensity for lurbinectedin and doxorubicin was $90.3 \%$ and $95.0 \%$, respectively. Of note, the absence of cardiac events related to changes in left ventricular ejection fraction either during dose escalation or in the expansion cohort suggest that lurbinectedin does not increase ventricular dysfunction over doxorubicin. ${ }^{18}$ Due to the incidence of febrile neutropenia, the use of growth colony-stimulating factors is mandatory for further studies.

\section{Strengths and Weaknesses}

A strength of this study was the inclusion of an expanded cohort to evaluate a new recommended dose. A limitation of this analysis is that data came from a phase I study with overall response rate assessed by the investigators and a small cohort of patients, which limits the conclusions that can be drawn. Furthermore, no molecular tests were done to check biomarkers in the population evaluated; so, for instance, no comparison with agents in advanced/recurrent mismatch repair deficient disease can be done.

\section{Implications for Practice and Future Research}

Because second-line treatment of advanced endometrial cancer is an unmet medical need, based on the preliminary efficacy results observed, further clinical development of the doxorubicin plus lurbinectedin combination is warranted in relapsed endometrial cancer. This combination may provide a further option for patients with disease unlikely to be cross resistant with newer therapeutic paradigms such as single agent immunotherapy and pembrolizumab/ lenvatinib.

\section{CONCLUSIONS}

Promising antitumor activity and a tolerable safety profile have been found for the combination of doxorubicin $40 \mathrm{mg} / \mathrm{m}^{2}$ plus lurbinectedin $2.0 \mathrm{mg} / \mathrm{m}^{2}$ on day 1 every 3 weeks in patients with advanced endometrial cancer. The combination was generally well tolerated, with manageable and predictable myelotoxicity as the main toxicity.

\section{Author affiliations \\ 'Guy's and St Thomas' NHS Foundation Trust, London, UK \\ ${ }^{2}$ START Madrid-FJD, Hospital Fundación Jiménez Díaz, Madrid, Spain \\ ${ }^{3}$ START Madrid-CIOCC, Centro Integral Oncológico Clara Campal, Madrid, Spain \\ ${ }^{4}$ Hospital Universitario Ramón y Cajal, Madrid, Spain \\ ${ }^{5}$ PharmaMar SA, Colmenar Viejo, Madrid, Spain \\ ${ }^{6}$ Instituto Valenciano de Oncología, Valencia, Spain \\ ${ }^{7}$ Hospital Universitari Vall d'Hebron, Barcelona, Spain \\ ${ }^{8}$ Clinical Development, PharmaMar SA, Colmenar Viejo, Spain \\ ${ }^{9} \mathrm{NIHR}$ UCLH Clinical Research Facility, London, UK}

\section{Presented at}

Preliminary results of this study have been presented at the American Society of Clinical Oncology 53rd Annual Meeting. 'Forster et al. Activity of lurbinectedin (PM01183) as single agent and in combination in patients with endometrial cancer. J Clin Oncol 2017, 35: Abstract 5586'.

Acknowledgements We gratefully acknowledge the patients, their families and investigator teams.

Contributors RK: conceptualization, investigation, resources, writing —original draft, writing—review and editing. VM: investigation, resources, writing—review and editing. VB: investigation, resources, writing —review and editing. EMG: investigation, resources, writing - review and editing. CK: conceptualization, methodology, writing — review and editing, supervision. IR: investigation, resources, writing — review and editing. EC: investigation, resources, writing — review and editing. NB: investigation, resources, writing - review and editing. JAL-V: methodology, writing — review and editing, supervision. MS: methodology, formal analysis, writing — review and editing. VA: methodology, writing —original draft, writing — review and editing. AZ: methodology, writing — review and editing, supervision. MF: investigation, resources, writing — review and editing.

Funding This work was supported by Pharma Mar, S.A. Grants from the Centro para el Desarrollo Tecnológico Industrial (CDTI) were obtained. Rebecca Kristeleit and Martin Forster were supported by the UCL/UCLH NIHR Biomedical Research Center and run early phase studies in the NIHR UCLH Clinical Research Facility supported by the UCL ECMC

Competing interests RK reports personal fees from Eisai. GSK, Clovis, Basilea, AstraZeneca, Roche, InCyte, and PharmaMar; non-financial support from GSK, Clovis, Basilea, AstraZeneca and Roche; and a grant from Clovis, outside the submitted work. VM reports personal fees and other (travelling support, speaker's bureau) from Bayer, BMS, Pieris, Roche, Janssen, Regeneron/Sanofi and Nanobiotix, and a grant from Medscape/Bayer, outside the submitted work. VB reports personal fees from Oncoart, Guidepoint, PUMA, Cytomx, Loxo Therapeutics, and institutional financial support for clinical trials from Abbvie, ACEO, Adaptaimmune, Amcure, AMGEN, AstraZeneca, BMS Cytomx, GSK, Genentech/ Roche, H3, Incyte, Janssen, Kura, Lilly, Loxo, Nektar, Macrogenics, Menarini, Merck, Merus, Nanobiotix, Novartis, Pfizer, PharmaMar, Principia, PUMA, Sanofi, Taiho, Tesaro, BeiGene, Transgene, Takeda, Incyte, Innovio, MSD, Psi0xus, Seattle Genetics; Mersana; GSK; Daiichi; Nektar; Astellas; ORCA; Boston Therapeutics; Dynavax, DebioPharm, Boehringer Ingelheim, Regeneron, Millennium, Synthon, Spectrum, Rigontec, and Zenith, outside the submitted work. EMG reports advisory/consultancy honorariums from AstraZeneca-MSD, Clovis Oncology, GSK-Tesaro, PharmaMar and Roche; she has received speaker bureau/expert testimony honorariums from AstraZeneca, PharmaMar, Roche and GSK; and has received travel/accommodation/expenses from Roche, Tesaro: A GSK Company and Baxter. IR reports personal fees and non-financial support from Pharmamar; grants, personal fees and non-financial support from Roche; personal fees from Clovis; personal fees from GSK; and grants, personal fees and non-financial support from AstraZeneca, outside the submitted work. EC reports grants and personal fees from Astellas, Novartis, Nanobiotix, Pfizer, Janssen-Cilag, PsiOxus Therapeutics, Merck, BMS, Seattle Genetics, Boehringer Ingelheim, AstraZeneca, Roche/Genentech, Servier, Celgene, Abbvie, Amcure, Alkermes, PharmaMar, BeiGene and GLG; personal fees from Medscape, Gilead, Pierre Fabre, Cerulean Pharma, EUSA, Gerhmann Consulting, Guidepoint, OncoDNA; and grants from ACE0, Adaptaimmune, AMGEN, Cytomx, GSK, H3, Incyte, Kura, Lilly, Nektar, Loxo, Macrogenics, Menarini, Merus, Principia, PUMA, Sanofi, Taiho, Tesaro, Transgene, Takeda, Innovio, MSD, Mersana, Daiichi, ORCA, Boston Therapeutics, Dynavax, DebioPharm, Regeneron, Millenium, Synthon, Spectrum and Rigontec, outside the submitted work. NB reports personal fees and non-financial support from BMS and Merck Serono, and personal fees from AstraZeneca, BioNTech, Eisai and MSD, outside the submitted work. CK, JAL-V, MS, VA and AZ report grants from the Centro para el Desarrollo Tecnológico Industrial (CDTI) during the conduct of the study; and personal fees for salary as full time employee and stock ownership from Pharma Mar, outside the submitted work. MF reports grants from Merck Educational Grant for EACH study, grants from MSD Educational Grant for POPPY study, grants from Boehringer Ingelheim Educational Grant for DARWIN1 study, grants from AstraZeneca Educational Grant for ORCA2 study, personal fees from Achilles Advisory and Consultancy Work, personal fees from AstraZeneca Advisory and Consultancy Work, personal fees from BMS Advisory and Consultancy Work, personal fees from Merck Advisory and Consultancy Work, personal fees from MSD Advisory and Consultancy Work, personal fees from Nanobiotix Advisory and Consultancy Work, personal fees from Novartis Advisory and Consultancy Work, personal fees from Pfizer Advisory and Consultancy Work, personal fees from Pharmamar Advisory and Consultancy Work, personal fees from Roche Advisory and Consultancy Work, personal fees from Takeda Advisory and Consultancy Work, personal fees from Bayer Advisory and Consultancy Work, outside the submitted work.

Patient consent for publication Not applicable.

Provenance and peer review Not commissioned; externally peer reviewed.

Data availability statement All data relevant to the study are included in the article or uploaded as supplementary information. Individual participant data are not publicly available since this requirement was not anticipated in the study 


\section{Original research}

protocol considering that this trial started patient enrolment in 2014. Clinical trial summary results were uploaded to the European Clinical Trials Database (EudraCT https://eudract.ema.europa.eu) and ClinicalTrials.gov (identifier: NCT01970540).

Open access This is an open access article distributed in accordance with the Creative Commons Attribution Non Commercial (CC BY-NC 4.0) license, which permits others to distribute, remix, adapt, build upon this work non-commercially, and license their derivative works on different terms, provided the original work is properly cited, an indication of whether changes were made, and the use is noncommercial. See: http://creativecommons.org/licenses/by-nc/4.0/.

\section{ORCID iD}

Vicente Alfaro http://orcid.org/0000-0002-0150-2390

\section{REFERENCES}

1 Makker V, Hensley ML, Zhou Q, et al. Treatment of advanced or recurrent endometrial carcinoma with doxorubicin in patients progressing after paclitaxel/carboplatin: Memorial Sloan-Kettering cancer center experience from 1995 to 2009. Int J Gynecol Cancer 2013;23:929-34.

2 NCCN clinical practice guidelines in oncology (NCCN guidelines): uterine neoplasms. version 03, 2021. Available: http://wwwnccnorg/ professionals/defaultaspx

3 Charo LM, Plaxe SC. Recent advances in endometrial cancer: a review of key clinical trials from 2015 to 2019. F1000Res 2019;8. doi:10.12688/f1000research.17408.1. [Epub ahead of print: 12 Jun 2019].

4 Fountzilas E, Kotoula V, Pentheroudakis G, et al. Prognostic implications of mismatch repair deficiency in patients with nonmetastatic colorectal and endometrial cancer. ESMO Open 2019;4:e000474.

5 Singh S, Jaigirdar AA, Mulkey F, et al. FDA approval summary: Lurbinectedin for the treatment of metastatic small cell lung cancer. Clin Cancer Res 2021;27:2378-82.

6 Elez ME, Tabernero J, Geary D, et al. First-in-human phase I study of Lurbinectedin (PM01183) in patients with advanced solid tumors. Clin Cancer Res 2014;20:2205-14.

7 Calvo E, Moreno V, Flynn M, et al. Antitumor activity of lurbinectedin (PM01183) and doxorubicin in relapsed small-cell lung cancer: results from a phase I study. Ann Oncol 2017;28:2559-66.

8 Singal PK, lliskovic N. Doxorubicin-induced cardiomyopathy. N Engl J Med 1998;339:900-5.

9 Jordan K, Kasper C, Schmoll H-J. Chemotherapy-induced nausea and vomiting: current and new standards in the antiemetic prophylaxis and treatment. Eur J Cancer 2005;41:199-205.

10 Delgado A, Guddati AK. Clinical endpoints in oncology - a primer. Am J Cancer Res 2021;11:1121-31.

11 Olmedo ME, Forster M, Moreno V, et al. Efficacy and safety of lurbinectedin and doxorubicin in relapsed small cell lung cancer. results from an expansion cohort of a phase I study. Invest New Drugs 2021;39:1275-83.

12 Arora S, Balasubramaniam S, Zhang W, et al. FDA approval summary: pembrolizumab plus lenvatinib for endometrial carcinoma, a collaborative international review under project Orbis. Clin Cancer Res 2020;26:5062-7.

13 Makker V, Taylor MH, Aghajanian C, et al. Lenvatinib plus pembrolizumab in patients with advanced endometrial cancer. J Clin Oncol 2020;38:2981-92.

14 McMeekin S, Dizon D, Barter J, et al. Phase III randomized trial of second-line ixabepilone versus paclitaxel or doxorubicin in women with advanced endometrial cancer. Gynecol Oncol 2015;138:18-23.

15 Aghajanian C, Sill MW, Darcy KM, et al. Phase II trial of bevacizumab in recurrent or persistent endometrial cancer: a gynecologic Oncology Group study. J Clin Oncol 2011;29:2259-65.
16 Forster MD, Moreno V, Boni V, et al. Activity of lurbinectedin (PM01183) as single agent and in combination in patients with endometrial cancer. JCO 2017;35:5586.

17 Miller DS, Scambia G, Bondarenko I, et al. ZoptEC: phase III randomized controlled study comparing zoptarelin with doxorubicin as second line therapy for locally advanced, recurrent, or metastatic endometrial cancer (NCT01767155). JCO 2018;36:5503.

18 Stone JR, Kanneganti R, Abbasi M, et al. Monitoring for chemotherapy-related cardiotoxicity in the form of left ventricular systolic dysfunction: a review of current recommendations. JCO Oncol Pract 2021;17:228-36.

19 Thigpen JT, Blessing JA, Lagasse LD, et al. Phase II trial of cisplatin as second-line chemotherapy in patients with advanced or recurrent endometrial carcinoma. A Gynecologic Oncology Group study. Am J Clin Oncol 1984;7:253-6.

20 Pawinski A, Tumolo S, Hoesel G, et al. Cyclophosphamide or ifosfamide in patients with advanced and/or recurrent endometrial carcinoma: a randomized phase II study of the EORTC Gynecological Cancer Cooperative Group. Eur J Obstet Gynecol Reprod Biol 1999;86:179-83.

21 Moore DH, Blessing JA, Dunton C, et al. Dactinomycin in the treatment of recurrent or persistent endometrial carcinoma: a phase II study of the Gynecologic Oncology Group. Gynecol Oncol 1999;75:473-5.

22 Garcia AA, Blessing JA, Nolte S, et al. A phase II evaluation of Weekly docetaxel in the treatment of recurrent or persistent endometrial carcinoma: a study by the gynecologic Oncology Group. Gynecol Oncol 2008;111:22-6.

23 Di Legge A, Trivellizzi IN, Moruzzi MC, et al. Phase 2 trial of nonpegylated doxorubicin (Myocet) as second-line treatment in advanced or recurrent endometrial cancer. Int $J$ Gynecol Cancer 2011;21:1446-51.

24 Muggia FM, Blessing JA, Sorosky J, et al. Phase II trial of the pegylated liposomal doxorubicin in previously treated metastatic endometrial cancer: a Gynecologic Oncology Group study. J Clin Oncol 2002;20:2360-4.

25 Escobar PF, Markman M, Zanotti K, et al. Phase 2 trial of pegylated liposomal doxorubicin in advanced endometrial cancer. J Cancer Res Clin Oncol 2003;129:651-4.

26 Rose PG, Blessing JA, Lewandowski GS, et al. A phase II trial of prolonged oral etoposide (VP-16) as second-line therapy for advanced and recurrent endometrial carcinoma: a Gynecologic Oncology Group study. Gynecol Oncol 1996;63:101-4.

27 Tait DL, Blessing JA, Hoffman JS, et al. A phase II study of gemcitabine (gemzar, LY188011) in the treatment of recurrent or persistent endometrial carcinoma: a gynecologic oncology group study. Gynecol Oncol 2011;121:118-21.

28 Sutton GP, Blessing JA, Homesley HD, et al. Phase II study of ifosfamide and mesna in refractory adenocarcinoma of the endometrium. A Gynecologic Oncology Group study. Cancer 1994;73:1453-5.

29 Dizon DS, Blessing JA, McMeekin DS, et al. Phase II trial of ixabepilone as second-line treatment in advanced endometrial cancer: Gynecologic Oncology Group trial 129-P. J Clin Oncol 2009;27:3104-8.

30 Fracasso PM, Blessing JA, Molpus KL, et al. Phase II study of oxaliplatin as second-line chemotherapy in endometrial carcinoma: a Gynecologic Oncology Group study. Gynecol Oncol 2006;103:523-6.

31 Lincoln S, Blessing JA, Lee RB, et al. Activity of paclitaxel as second-line chemotherapy in endometrial carcinoma: a gynecologic Oncology Group study. Gynecol Oncol 2003;88:277-81.

32 Miller DS, Blessing JA, Lentz SS, et al. A phase II trial of topotecan in patients with advanced, persistent, or recurrent endometrial carcinoma: a Gynecologic Oncology Group study. Gynecol Oncol 2002;87:247-51. 